\title{
Satirisme Cerdas Iklan Djarum 76 Filter Gold Versi Caleg Cerdas (Analisis Semiotika Roland Barthes)
}

\author{
Octav Noriega, Gregorius Genep Sukendro \\ octav.915160082@stu.untar.ac.id,geneps@fikom.untar.ac.id \\ Fakultas Ilmu Komunikasi Universitas Tarumanagara
}

\begin{abstract}
This research discusses satirism in Djarum 76 Filter Gold advertisement - Caleg Cerdas version. This research uses Roland Barthes's semiotic thinking approach. Where the meaning of the message is obtained from the first sign (denotation) in the form of audiovisual that appears and captured by our five senses and has another meaning behind the first meaning (connotation) and the second meaning (myth). Djarum 76 Filter Gold advertisement Caleg Cerdas version aired during the democratic party took place or before May 21, 2019. The element of satirism in this ad is displayed with humor where these elements as a whole can be found scene by scene in this ad. From the results of the study there were six (6) types of satirism / satire for the legislative candidates: Empty Brain, Ecek-Ecek Brain, Off-Air Brain, Wani Piro Brain, Dugem Brain and Music. After concluding, it can be concluded that there is a satirism contained in Djarum 76 Filter Gold adverstisment - Caleg Cerdas version is legitaslitve candidates are stupid, believes in mystical things and hopes somethins instant without working hard.
\end{abstract}

Keyword: djarum 76 advertisement, roland barthes, semiotics analysis, satirism, smart legislative candidates

\begin{abstract}
Abstrak
Penelitian ini membahas tentang bagaimana gaya satirisme cerdas dalam iklan Djarum 76 Filter Gold versi Caleg Cerdas. Penelitian ini menggunakan pendekatan pemikiran semiotika Roland Barthes. Dimana makna pesan tersebut diperoleh dari tanda pertama (denotasi) berupa audio visual yang muncul dan ditangkap oleh panca indera kita serta memiliki makna lain dibalik makna pertama (konotasi) dan makna kedua (mitos). Iklan Djarum 76 Filter Gold versi Caleg Cerdas ditayangkan saat pesta demokrasi berlangsung atau sebelum tanggal 21 Mei 2019. Unsur satirisme pada iklan ini ditampilkan dengan penuh humor dimana unsur-unsur ini secara keseluruhan dapat ditemukan adegan per adegan dalam iklan ini. Dari hasil penelitian terdapat enam(6) macam sindiran/satire untuk para caleg yaitu: Otak Kosong, Otak EcekEcek, Otak Off-Air, Otak Wani Piro, Otak Dugem dan Musik. Setelah disimpulkan, dapat disimpulkan terdapat makna satir yang terkandung pada iklan Djarum 76 Filter Gold versi Caleg Cerdas berupa seorang caleg yang kurang pintar yang mempercayai hal klenik atau mistis dan mengharapkan suatu hal yang instan tanpa bekerja keras.
\end{abstract}

Kata Kunci: analisi semiotika, iklan Djarum 76, caleg cerdas, Roland Barthes, satirisme

\section{Pendahuluan}

Pemilu merupakan proses kedaulatan rakyat yang diselenggarakan secara langsung, umum, bebas, rahasia, jujur, dan adil dalam Negara Kesatuan Republik Indonesia (NKRI) berdasarkan Pancasila dan Undang-undang Dasar Republik Indonesia tahun 1945. Pemilu diselenggarakan oleh Komisi Pemilihan Umum (KPU) dan Badan Pengawasan Pemilu Umum (Bawaslu). Pada tahun 2019 merupakan pemilu 
serentak pertama di Indonesia dalam sejarah. Selain memilih Presiden dan Wakil Presiden, di pemilu 2019 rakyat juga memilih anggota DPR, DPD, DPRD Provinsi, dan DPRD Kabupaten/Kota. Oleh karena itu iklan politik terlihat marak di berbagai media sebagai salah satu bentuk partisipasi pesta demokrasi. Beberapa partai politik juga memasang iklan politik untuk membujuk masyarakat agar memilih mereka. Maraknya iklan politik pada saat ini membuat produk lain juga ikut meramaikan Pesta Demokrasi dengan beriklan mengenai politik dan meramaikan pemilu 2019. Salah satu iklan tersebut adalah iklan rokok.

Pihak pengiklan rokok menampilkan iklan dengan citra yang baik, bagus dan unik melalui iklan rokok yang ditayangkan. Iklan rokok Djarum 76 mempunyai keunikan tersendiri. Iklan Djarum 76 seringkali menampilkan tema-tema sosial yang dapat dipahami sebagai bentuk kritikan sosial kepada pihak-pihak tertentu. Dengan memunculkan sosok jin dalam setiap iklannya, Djarum 76 berusaha menceritakan produknya sebagai produsen yang konsen terhadap masalah-masalah sosial yang terjadi. Djarum 76 peduli akan masalah-masalah sosial yang ada, kemudian dimunculkan dalam bentuk parodi namun sarat akan makna dan kritik sosial. Salah satu iklannya adalah Djarum 76 Filter Gold versi Caleg Cerdas. Dalam 6 iklan yang mempunyai konsep yang sama dengan durasi 30 detik ini menggambarkan seorang caleg yang meminta kepada jin untuk mencari caleg cerdas. Lalu ketika jin melihat apa yang dipikirkan caleg tersebut, jin tidak melihat apa-apa. Jin pun berkata "tidak mungkin atau impossible" dan menertawai caleg tersebut.

Dalam iklan tersebut peneliti ingin meneliti tentang gaya satirisme cerdas yang ada pada iklan tersebut. Satirisme adalah sebuah gaya menyindir, mengolok-olok, melecehkan bahkan menertawakan suatu kebodohan. Satirisme cerdas yang ditampilkan dalam iklan Djarum 76 Filter Gold versi Caleg Cerdas memungkinan untuk dapat dimaknai dengan lebih fokus melalui analisis semiotik. Dari setiap iklan yang ditayangkan pasti memiliki makna tersendiri, lewat hubungan antara tanda (Sign), penanda (Signifier), dan petanda (Signified) akan membantu peneliti kearah makna tersembunyi dari iklan tersebut. Penelitian ini akan memperlihatkan bagaimana gaya satirisme cerdas yang dilakukan dalam iklan Djarum 76 Filter Gold versi Caleg Cerdas. Iklan yang ditayangkan berlangsung pada masa kampanye. Dalam iklan tersebut menampilkan sindiran untuk para caleg yang biasanya ketika sudah terpilih hasil kerjanya tidak terlihat dan perkembangan pembangunan infrastruktur juga hamban. Kebanyakan iklan politik akan menampilkan caleg yang berintelejen, mempunyai berbagai kelebihan. Namun iklan Djarum 76 ini justru membuat suatu sindiran yang bagus dan unik untuk mengemukakan peristiwa nyata yang terjadi di Indonesia pasca pemilu. Dari iklan tersebut, maka peneliti merasa perlu untuk menganalisis semiotika terhadap iklan Djarum 76 Filter Gold versi Caleg Cerdas. Berdasarkan alasan tersebut maka judul skripsi yang akan penulis buat adalah: Satirisme Cerdas Iklan Djarum 76 versi Caleg Cerdas.

Rumusan Masalah

a. Makna denotatif dan konotatif yang terungkap dari iklan Djarum 76 Filter Gold versi Caleg Cerdas?

b. Bagaimana gaya satirisme cerdas yang digunakan dalam iklan Djarum 76 Filter Gold versi Caleg Cerdas?

Tujuan Penelitian

a. Mengetahui pesan iklan Djarum 76 Filter Gold versi Caleg Cerdas

b. Mengetahui bagaimana satirisme cerdas dalam iklan Djarum 76 Filter Gold versi Caleg Cerdas 
Octav Noriega, Gregorius Genep Sukendro: Satirisme Cerdas Iklan Djarum 76 Filter Gold versi Caleg Cerdas (Analisis Semiotik Roland Barthes)

\section{Semiotika Roland Barthes}

Roland Barthes adalah seorang ahli semiotik yang sangat terjebak dan berperan cukup penting dalam membangun pengetahuan mengenai semiotik (dikutip dalam jurnal berjudul "Representasi Kampanye Politik Dalam Game (Analisis Semiotik Dalam Game Jokowi Go! Dan Game Prabowo The Asian Tiger pada tanggal 16 Januari 2020 di di Jurnal Fikom Untar http://dx.doi.org/10.24912/jk.v7i1.10).

Tanda adalah kesatuan dari suatu bentuk penanda (signifier) dengan sebuah ide atau (signified). Dengan kata lain, penanda adalah "bunyi yang bermakna" atau "coretan yang bermakna". Jadi, penanda adalah aspek material dari bahasa: apa yang dikatakan atau didengar dan apa yang ditulis atau dibaca (Sobur, 2017:46). Petanda adalah gambaran mental, yakni fikiran atau konsep aspek mental dari bahasa. (Sobur, 2009:125). Pemahaman mengenai makna denotasi dan konotasi dalam kajian barthes merujuk pada adanya hubungan tanda, penanda dan petanda yang terjalin dalam satu rangkaian kebutuhan simbol makna.

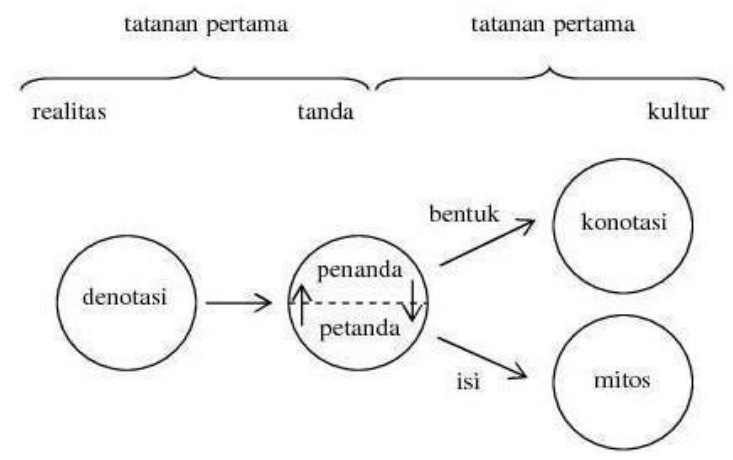

Gambar 1. Signifikasi Dua Tahap Barthes

Signifikan tahap pertama merupakan hubungan antara signifier dan signified di dalam sebuah tanda terhadap realitas eksternal. Barthes menyebutnya sebagai denotasi, yaitu makna paling nyata dari tanda. Konotasi adalah istilah yang digunakan Barthes untuk menunjukkan signifikan tahap kedua. Hal ini menggambarkan interaksi yang terjadi ketika tanda bertemu dengan perasaan atau emosi dari pembaca serta nilainilai dari kebudayaannya. Pemilihan kata-kata kadang merupakan pilihan terhadap konotasi, misalnya kata "penyuapan" dengan "memberi uang pelicin". Dengan kata lain, denotasi adalah apa yang digambarkan tanda terhadap sebuah objek; sedangkan konotasi adalah bagaimana menggambarkannya (Sobur, 2009).

Signifikan tahap kedua berhubungan dengan isi, tahap bekerja melalui mitos. Mitos adalah bagaimana kebudayaan menjelaskan atau memahami beberapa aspek tentang realitas atau gejala alam. Mitos merupakan produk kelas sosial yang sudah mempunyai dominasi. Mios primitive, misalnya, mengenai hidup dan mati, manusia dan dewa, dan sebagainya. Sedangkan mitos masa kini misalnya, mengenai feminitas, maskulinitas, ilmu pengetahuan dan kesuksesan (Sobur, 2009).

Mitos menurut KBBI adalah cerita suatu bangsa tentang dewa dan pahlawan zaman dahulu, mengandung penafsiran tentang asal-usul semesta alam, manusia, dan bangsa tersebut mengandung arti mendalam yang diungkapkan dengan cara gaib. Sedangkan mitologi menurut KBBI adalah ilmu yang terbarukan mengenai mitos.

a. Konsep Satir

Satir adalah gaya bahasa dalam sastra yang digunakan untuk menyatakan sindiran terhadap suatu keadaan atau seseorang. Selain sindiran, satire juga dapat dimaknai sebagai ejekan. Dalam bentuk apapun, satire digunakan agar orang yang 
disindir atau diejek mau mengubah perilakunya menjadi baik kembali. Biasanya sindiran yang satiris disampaikan dalam bentuk ironi, sarkasme, ataupun parodi (Bayuadhy, 2016). Sedangkan satire menurut Berger (1997) adalah penggabungan antara unsur ironi, sarkasme, dan biasanya dikemas dalam bentuk humor. Menurut Oxford Dictionary, satire memiliki tujuan dalam mengekspos dan mengkritik kesalahan orang, sehingga sebuah satire mempunyai fungsi kritik.

\section{Metode Penelitian}

Dari beberapa metode penelitian kualitatif yang ada, penulis memilih metode penelitian interaksi simbolik. Pendekatan ini berasumsi bahwa pengalaman manusia ditengahi penafsiran mendalam. Objek, orang, situasi, dan peristiwa tidak memiliki penafsirannya sendiri. Penafsiran bukanlah tindakan bebas dan bukan pula ditentukan oleh kekuatan manusia atau bukan. Orang-orang menafsirkan sesuatu dengan bantuan orang lain seperti peneliti terdahulu, penulis, keluarga, pemeran di televisi, dan pribadi-pribadi yang ditemuinya dalam latar tempat mereka bekerja atau bermain (Moleong, 2011).

Dari pernyataan diatas, penulis berpendapat bahwa metode penelitian interaksi simbolik paling sesuai dalam penelitian ini. Hal ini dikarenakan metode interaksi simbolik merupakan metode yang paling cocok dengan teori semiotik konotasi Barthes yang akan penulis gunakan. Penulis juga perlu melakukan signifikan iklan Djarum 76 Filter Gold versi Caleg Cerdas secara mendalam dibantu dengan teori analisis semiotik konotasi Roland Barthes.

\section{Hasil Temuan dan Analisis}

Makna denotatif dari iklan Djarum 76 Filter Gold versi Caleg Cerdas iklan "Otak Kosong", "Otak Ecek-Ecek", "Otak Off-Air", "Otak Wani Piro" dan "Otak Dugem" adalah seorang caleg yang tidak mempunyai solusi masalah yang sedang terjadi. Lalu caleg meminta kepada sosok jin lampu untuk dijadikan caleg cerdas dan sang jin tidak mengabulkan permintaan caleg karena isi dari otak caleg ternyata otak kosong, ecek-ecek (pura-pura), titttt (tidak sambung), wani piro (uang) dan otak dugem. Lalu pada iklan versi "minta musik", caleg minta musik dan Om Jin mengabulkannya. Seketika musik pun dimainkan dan sekretaris perempuan mulai menari mengikuti irama musik dugem yang dimainkan. Lalu Om Jin bertanya kembali kepada caleg "gak pengen minta yang lain?", caleg menjawab enggak. Om Jin dengan sigap berkata kepada Caleg "Cerdas".

Setelah diteliti enam (6) iklan tersebut adegan per adegan tokoh pria tersebut memiliki makna konotatif:

a. Seorang Calon Anggota Legislatif (Caleg) atau pejabat negara

Terdapat tiga (3) poin yang dapat menunjukkan bahwa tokoh pria tersebut adalah calon anggota legislatif atau caleg:

1. Kalimat yang dikeluarkan oleh tokoh pria "Jadi Caleg Cerdas"

Dari kalimat tokoh pria tersebut sudah bisa dijelaskan bahwa tokoh pria tersebut adalah calon anggota legislatif atau pejabat negara yang akan maju menjadi anggota legislatif di periode selanjutnya.

2. Busana batik

Busana batik kerap digunakan oleh seorang pejabat negara ketika menghadiri suatu acara resmi atau sedang bekerja. 


\section{Popularitas}

Terlihat di awal scene tokoh pria (caleg) tersebut dikerumunan oleh para wartawan. Hal ini menunjukkan tokoh pria tersebut merupakan tokoh penting di suatu tatanan negara.

b. Mengharapkan suatu hal dengan instan

Ketika tokoh pria(caleg) bertemu dengan sosok jin di iklan Djarum 76 Filter Gold versi Caleg Cerdas, terlihat tokoh pria tersebut meminta kepada jin untuk dijadikan menjadi caleg cerdas. Padahal secara rasional untuk menjadi cerdas tidak dapat dengan cara instan, harus melalui proses belajar yang panjang dan memakan waktu tidak sedikit.

c. Percaya akan hal-hal klenik dan mistis

Masyarakat Indonesia masih sangat mempercayai hal klenik dan mistis. Hal ini didukung dari suatu artikel di Kompas.TV. Artikel ini berisikan tentang suatu fenomena yang muncul ketika menjelang ujian CPNS berlangsung. Pada seleksi CPNS 2018 petugas menemukan tak sedikit peserta ujian membawa jimat, gunting, bawang, brambang, dan sebagainya di kantong celananya. Fenomena memakai jimat hingga menemui dukun agar terpilih sudah menjadi hal yang lumrah bagi masyarakat Indonesia.

d. Kurang Pintar atau Cerdas (Bodoh)

Terdapat dua (2) poin yang menunjukkan tokoh pria (caleg) kurang pintar yaitu:

1. Ketika tokoh pria(caleg) ditanyai para wartawan, dan caleg tersebut tidak bisa menjawab.

2. Ketika tokoh pria meminta kepada jin untuk dijadikan menjadi caleg cerdas.

e. Tidak Tamak atau serakah

Pada iklan keenam caleg meminta musik kepada jin, dan menolak permintaan kedua yang ditawarkan oleh jin. Tidak biasanya sosok Om Jin dalam iklan ini menawarkan permintaan kedua. Hal ini membuktikan caleg pada iklan keenam itu cerdas. Untuk menjadi cerdas salah satunya harus tidak boleh tamak atau serakah.

Makna konotatif keenam iklan yaitu:

a. Otak kosong: caleg yang tidak mempunyai gagasan atau ide-ide dalam menghadapi masalah yang terjadi.

b. Otak ecek-ecek: caleg yang hidup dengan kepura-puraan, menyuruh orang lain untuk menyelesaikan masalahnya hingga mereka sendiri tidak mempunyai kemampuan untuk menyelesaikan masalah.

c. Otak off-air: caleg yang tertutup, tidak ingin menjadi perpanjangan tangan rakyat di pemerintah dan hanya mementingkan popularitas dan kekayaan sendiri

d. Otak wani piro: caleg yang hanya berpikir tentang duit, dan bisa mengarah kepada kasus korupsi yang kerap terjadi.

e. Otak dugem: caleg yang hanya berpikir senang-senang saja. Seharusnya caleg mempunyai tugas mengayomi rakyat dan negara. Tetapi caleg di iklan kelima malah mengayomi diri sendiri.

f. Musik: caleg iklan ini merupakan caleg yang tidak tamak. Dia diberikan dua (2) permintaan oleh jin tetapi dia malah menolak dan hanya meminta musik saja sebagai penghibur kerja.

Dari makna konotatif dan denotatif yang telah dijelaskan di atas, maka iklan Djarum 76 Filter Gold versi Caleg Cerdas memiliki mitos bahwa masyarakat masih mempercayai adanya sesuatu yang klenik, mistis atau gaib, dan jauh dari unsur 
rasionalitas seperti sosok jin yang dipercaya dapat digunakan untuk menggapai suatu tujuan.

Satire adalah gaya bahasa dalam sastra yang digunakan untuk menyatakan sindiran terhadap suatu keadaan atau seseorang, bagaimana sang tokoh meminta untuk dijadikan caleg cerdas namun sang jin tidak mengiyakan malah kembali menyindir dan mengolok-olok caleg yang bodoh tersebut (Bayuadhy, 2016). Dari keenam iklan yang telah diteliti, peneliti menemukan gaya satirisme cerdas yang digunakan adalah:

a. Otak kosong: Caleg yang tidak mempunyai latar belakang pendidikan poltik, tapi tetap terjung di politik.

b. Otak ecek-ecek: caleg yang tidak mempunyai kemampuan untuk menyelesaikan masalah yang kerap terjadi.

c. Otak off-air: caleg yang hanya mementingkan popularitas dan memupuk kekayaan sendiri.

d. Otak wani piro: caleg yang sering terkena kasus korupsi

e. Otak dugem: caleg yang melalaikan tugasnya di tatanan negara dan hanya bersenang-senang, seperti tidur saat rapat.

Beberapa hal tentang satirisme ketika caleg yang meminta untuk dijadikan caleg cerdas juga ditemukan dalam iklan Djarum 76 Filter Gold versi Caleg Cerdas berupa budaya instan, malas belajar atau bekerja keras untuk mencapai sebuah tujuan, mata duitan (berpikir memperkaya diri), mementingkan popularitas sendiri sehingga melupakan tugas utamanya, hal tersebut direpresentasikan dengan meminta sesuatu kepada jin. Hal ini juga merupakan sebuah sindiran sosial dikarenakan dalam era modern saat ini kepercayaan terhadap hal-hal berbau klenik yang tidak rasional masih kental dalam budaya masyarakat Indonesia.

\section{Kesimpulan}

Dari hasil analisis pada bab sebelumnya, penulis menyimpulkan: (1) makna denotasi dalam iklan Djarum 76 Filter Gold versi Caleg Cerdas dimana terdapat sebuah alur seorang tokoh yang ingin menjadi caleg cerdas, dalam prosesnya meminta bantuan kepada jin. Tetapi jin tidak mengabulkannya dan ketika caleg meminta musik, jin pun mengabulkannya. Akhirnya ketiga tokoh menari bersama mengiringi musik EDM. (2) Memiliki makna konotatif bahwa tokoh pria tersebut merupakan seorang Calon Anggota Legislatif yang kurang pintar yang mengharapkan suatu hal dengan instan dan masih percaya hal-hal klenik atau mistis. (3) Unsur mitos yang ditemukan dalam penelitian ini adalah masyarakat masih mempercayai adanya hal klenik atau mistis dan jauh dari unsur rasionalitas seperti hadirnya sosok Jin pada iklan Djarum 76 yang dipercaya dapat digunakan untuk mengabulkan segala permintaan. Lalu terdapat keyakinan bahwa masyarakat di negeri masih percaya dengan hal-hal yang berbau supranatural yang jauh dari kata masuk akal atau tidak rasional. Mitos lainnya adalah untuk menjadi cerdas atau pandai tidak bisa diraih dengan instan. Maka dari itu untuk menjadi cerdas harus rajin dan membutuhkan usaha yang besar tentunya. (4) Terdapat unsur satir yang baik seperti: unsur humor yang kuat, menyindir dan mengolok-olok tokoh dan kondisi politik di negeri ini. Iklan ini berjenis satir Horatian, dengan ciri menggunakan nada bicara yang ringan dan jenaka. Iklan ini juga memberitahukan upaya menjadi caleg sudah menjadi suatu budaya dengan upaya untuk meningkatkan popularitas, memperkaya diri sendiri dan mempunyai kekuasaan di tatanan negara. 


\section{Ucapan Terima Kasih}

Atas terselesaikannya penelitian ini, peneliti mengucapkan terima kasih kepada orang tua yang memberikan dukungan dan doa, Bapak Nigar Pandrianto, selaku dosen yang telah meluangkan waktu untuk ditanyai dan memberikan saran dalam penyusunan skripsi, serta teman-teman yang telah menemani dan membantu peneliti dalam penyusunan skripsi ini.

\section{Daftar Pustaka}

Azeharie, Suzy. (2017). Analisis Semiotika Representasi Keluarga Ideal Dalam Iklan Layanan Masyarakat Di Majalah Colours. Jakarta. Diakses tanggal 16 Januari 2020 di http://dx.doi.org/10.24912/jk.v7i2.18.

Beam, M. A., LaMarre, H. L., Landreville, K. D. (2009). The Irony of Satire "Political Ideology and the Motivation to See What You Want to See in The Colbert Report". International Journal of Press/Politics, Vol 14. NO. 2, Pages 212 231, Published April 2009

Baksin, Askurifai. (2006). Jurnalistik Televisi: Teori dan Praktik. Bandung: Simbiosa Rekatama Media

Bungin, Burhan. (2010). Penelitian Kualitatif: Komunikasi, Ekonomi, Kebijakan Publik dan Ilmu Sosial Lainnya. Jakarta: Kencana

Bayuadhy, Gesta. (2016). Tresna Jalaran Saka Arta, Satire ala Jawa terhadap Ketimpangan Perilaku Manusia. Yogyakarta: DIVA Press

Hertindha, Rindhi Rezqi. n.d. Kehidupan Remaja Pecinta Dunia Gemerlap. Universitas Yogyakarta

Craig, Stark. (2003). “What's Me Worry?” Teaching Media Literacy Through Satire and Mad Magazine. The Celaring House: A Journal of Educational Strategies, Issues and Ideas, Vol 76. No. 6, Published 3 April 2010, 309 pages

Gilkerson, Nathan David. (2012). Participatory Satire? Political Humor, the Colbert Super PAC Project, and the Colliding Worlds Of Late Night Comedy and Modern American Politics. University of Minnesota Ph.D. dissertation. September (2012). Major: Mass Communication. Advisor: Brian G. Southwell. 1 computer file (PDF); v, 265 pages, appendices A-B

Halim, Janne, Widayatmoko, Widayatmoko. (2015). Representasi Kampanye Politik Dalam Game (Analisis Semiotik Dalam Game Jokowi Go! Dan Game Prabowo The Asian Tiger). Jakarta. Diakses pada tanggal 16 Januari 2020 di Jurnal Fikom Untar http://dx.doi.org/10.24912/jk.v7i1.10

Lee, Monle \& Johnson, Carla. (2007). Prinsip-Prinsip Periklanan dalam Perspektif Global. Jakarta: Kencana

Mangkunegara, Awan P. (2005). Evaluasi Kinerja. Bandung: Refika Aditama

Moleong, Lexy J. (2011). Metodologi Penelitian Kualitatif. Bandung: PT Remaja Rosdakarya

Moleong, Lexy J. (2017). Metodologi Penelitian Kualitatif. Bandung: PT Remaja Rosdakarya

Moleong, Lexy J. (2018). Metodologi Penelitian Kualitatif. Bandung: PT Remaja Rosdakarya

Moriarty, Sandra. (2011). Advertising. (Edisi Kedelapan). Jakarta: Kencana.

Morisan. (2010). Periklanan, Komunikasi Pemasaran Terpadu. Jakarta: Kencana 
Prasetyo, Agung Mukti. (2016). Hubungan Antara Kesenangan Mendengarkan Musik Dangdut Dengan Tingkat Produktivitas Musik Dangdut Dengan Tingkat Produktivitas Karyawan Home Industry Trio di Desa Tegalwangi Kabupaten Tegal

Romli, Khomsahrial. (2016). Komunikasi Massa. Jakarta: PT Gramedia

Rukmana, Febri Inda. (2015). Pengaruh Musik DJ Terhadap Persepsi, Perilaku, dan Penampilan Para Pengunjung di Liquid Café Semarang. Universitas Negeri Semarang

Sastrabaryu, Akhmad Mu'izzanur. (2017). Penggunaan Virtual Studio Technology Dalam Proses Produksi Electronic Dance Music. Universitas Negeri Yogyakarta

Septiantya, Alva. (2016). Bentuk, Makna dan Tujuan Tuturan Sarkasme pada Serial Televisi House MD episode 1 sampai 5, musim 1. Universitas Gajah Mada

Silitonga, Immanuel D.B. (2019). Analisis Semiotika Makna Pesan Pada Iklan Djarum 76 versi “Caleg Cerdas-Otak Kosong”. Bahasa Indonesia Prima, Vol 1, No. 2 , 16 Agustus 2019. 46 halaman

Sobur, Alex. (2006). Analisis Teks Media. Bandung: PT. Remaja Rosdakarya Sobur, Alex. (2009). Analisis Teks Media. Bandung: PT. Remaja Rosdakarya Sobur, Alex. (2017). Semiotika Komunikasi. Bandung: PT. Remaja Rosdakarya Sugiyono. (2015). Metode Penelitian Kualitatif. Bandung: Alfabeta Widhyatama, Sila. (2012). Sejarah Musik dan Apresiasi Seni di Asia. Jakarta: PT. Balai Pustaka (Persero) 